\title{
Experimental Sensing and Density Functional Theory Study of an Ionic Liquid Mediated Carbon Nanotube Modified Carbon-paste Electrode for Electrochemical Detection of Metronidazole
}

\author{
Maliheh Saghravanian ${ }^{\mathrm{a}}$, Mahmoud Ebrahimi ${ }^{\mathrm{a}, \star}$, Zarrin Es'haghi ${ }^{\mathrm{b}}$ and S. Ali Beyramabadi ${ }^{\mathrm{a}}$ \\ ${ }^{a}$ Department of Chemistry, Mashhad Branch, Islamic Azad University, Mashhad, Iran. \\ ${ }^{b}$ Department of Chemistry, Payame Noor University (PNU), 19395-4697, Iran. \\ Received 30 May 2016, revised 27 November 2016, accepted 9 December 2016.
}

\begin{abstract}
A new highly sensitive sensor was prepared for metronidazole (MNZ) employing single-walled carbon nanotube (SWCNT) and 1-butyl-3-methylimidazolium tetrafluoroborate as ionic liquid (IL). The utilization of IL as a binder in the paste increased the response of the electrode. The performance of the obtained carbon paste electrode was examined by differential pulse voltammetry. Various factors like electrode composition, types of supporting electrolyte, $\mathrm{pH}$, stirring rate, scan rate were studied and optimized. The modified sensor demonstrated high recognition ability and sensitivity for MNZ when compared with the unmodified sensor. Moreover, the sensor also demonstrated good stability and acceptable reproducibility for the determination of MNZ. In the optimum experimental conditions, the current response of the electrochemical sensor studied for metronidazole solution and linearity was obtained in the range of $5.00 \times 10^{-5}$ to $5.00 \times 10^{-3} \mathrm{mg} \mathrm{L}^{-1}$, with a detection limit of $1.238 \times 10^{-5} \mathrm{mg} \mathrm{L}^{-1}$. The method was successfully used for the analysis of $\mathrm{MNZ}$ in the milk and egg samples with acceptable recoveries of $90.33-108.0 \%$. In addition, the non-covalent interactions of the metronidazole with the SWCNT were investigated employing the density functional theory (DFT) method.
\end{abstract}

KEYWORDS

Carbon paste electrode, metronidazole, differential pulse voltammetry, single-walled carbon nanotube, density functional theory, 1-butyl-3-methylimidazolium tetrafluoroborate.

\section{Introduction}

Metronidazole (MNZ) is a commonly used antibiotic for the treatment of bacterial infections in humans and pets. ${ }^{1}$ Determination of low amounts of MNZ is important in food and drug industries due to highly harmful effects of MNZ on human health. The chemical structure of metronidazole is similar to nitrobenzene. Metronidazole nitro group is reduced in a single four-electron step to an amino group in the absence of dissolved oxygen. ${ }^{2}$ Several methods have been reported for determining metronidazole, including various instrumental techniques such as chromatography, ${ }^{3-6}$ spectrophotometry, ${ }^{7-9}$ fluorescence $^{10}$ in addition to different electrochemical methods. ${ }^{11-18}$ Electrochemical methods are widely employed in analytical chemistry to determine pharmaceuticals ${ }^{19-21}$ due to the fast and easy preparation process, low cost, quick and reliable response. On the other hand, the feasibility of miniaturization and high sensitivity toward trace amount of analytes are other advantages of electrochemical methods. Furthermore, electrochemical methods could be applied in non-aqueous medium, it is not time-consuming and heating or extraction processes are not required either.

Working electrodes like Ion selective electrodes (ISEs) have a fundamental role in electrochemical methods. One type of ISEs, sensors based on PVC have been used for the determination of $\operatorname{drug}^{22}$, cations ${ }^{23-35}$ and anions ${ }^{36-37}$ with different ligands like crown ether ${ }^{38-42}$, porphyrin ${ }^{37,43-45}$ according to Gupta et al.

Carbon paste electrodes (CPEs) are another type of ISEs that

* To whom correspondence should be addressed. E-mail: ebrachem2007@yahoo.com are used as working electrodes in electrochemical methods in recent decades ${ }^{46-55}$. CPEs are prepared from graphite powder and organic liquid like paraffin. CPEs are commonly used electrodes in laboratories owing to their affordability, the simplicity of fabrication and renewal surface. In addition, reproducibility and high sensitivity for recognition and particularly their very low background current are other advantages of CPEs. ${ }^{56-59} \mathrm{CPEs}$ are applied as indicator electrodes in potentiometry and as working electrodes in voltammetry methods. Interestingly, carbon nanotubes (CNTs) ${ }^{60}$ have been applied in the past two decades due to their extreme mechanical strength, physical and chemical properties, high surface to area ratio, and excellent electrical conductivity properties. The conductivity property of CNTs has led to the application of CNTs in CPEs matrixes. Single-walled carbon nanotube (SWCNT) is one of the famous CNTs chemical structures that are applied in modified electrochemical sensors and biosensors. ${ }^{61}$ Nowadays, Ionic Liquids (ILs) are employed in the composition of modified electrode matrix instead of organic liquids in electrochemical sensors structure. ${ }^{62-65}$ ILs have advantages like wide electrochemical windows, high chemical and thermal stability in addition to high ionic conductivity.

Recently, Karimi-Maleh et al. applied the combination of nanomaterial and IL that led to significant increase in sensor response to the analyte and its selectivity. ${ }^{66-68}$

In this study, we applied the SWCNT-IL nano composite as a modifier for the carbon paste electrode based on the specific 
interaction of SWCNT with 1-butyl-3-methylimidazolium tetrafluoroborate as IL and their special properties for the first time. The difference between this study and other recent similar studies the utilization of IL instead of paraffin oil with SWCNT and graphite powder without additional modifiers like types of ionophore which enhanced the sensitivity, long-time stability, low detection limit and suitable reproducibility. This modified electrode could measure MNZ in sub-ppb level with high sensitivity when compared with other similar methods. Due to the increasing use of nanotechnology, investigations on the mechanism of nanoparticles operation is of great importance. ${ }^{69-70}$ In many cases, the covalent and non-covalent interactions of various molecules with the carbon nanotubes have been investigated. ${ }^{71-76}$ In addition to what has been earlier mentioned, non-covalent interactions of the MNZ with the SWCNT have been examined using the Density Functional Theory (DFT) approach that confirms the suitable orientation of drug interaction with the nanomaterial.

These results provide a new window for utilizing novel nanocomposite as identification element and sensitivity tool for determination of drugs and cations in the food industry or various media and investigation of theoretical calculations for the confirmation experimental work.

\section{Materials and Procedures}

\subsection{Reagents and Apparatus}

Metronidazole (Fig. 1a) was purchased from Aladdin Reagent Company (Shanghai, China). SWCNTs and MWCNTs were obtained from Tehran Research Institute of Petroleum Industry with the mean diameter of 10-15 nm for MWCNTs and 1-2 nm for SWCNTs, the length of 50-100 nm and the purity of $>95 \%$ for both of them. Graphite powder was provided from Lobachemi (Mumbai, India). The room temperature IL, 1-butyl-3-methylimidazolium tetrafluoroborate ([BMIM] $\left[\mathrm{BF}_{4}\right]$ ) (Fig. 1b) was acquired from Spectrochem. Milk and egg samples were provided from the local supermarket. Aqueous solutions were prepared with double distilled water. Other chemicals were analytical grade prepared from Merck. All chemicals of the present study were of analytical reagent grade and used directly without any purification.

Electrochemical measurements were performed on a threeelectrode system using the Metrohm model 797 VA Computrace polarography (Herisau, Switzerland). A platinum wire and an $\mathrm{Ag} / \mathrm{AgCl}$ electrode (saturated $\mathrm{KCl}$ ) were used as the counter and reference electrodes, respectively. Modified carbon paste sensors were applied as a working electrode. The cell was a one-section cell with an internal volume of $20 \mathrm{~mL}$. All experiments were usually directed at room temperature. Differential pulse voltammetry was applied for the determination of MNZ under the optimized conditions (pulse amplitude $/ 90 \mathrm{mV}$; pulse time/40 ms). A Metrohm model $780 \mathrm{pH}$-meter (Herisau, Switzerland) with a combined glass electrode was utilized for $\mathrm{pH}$ controlling, and solutions stirred with a Heidolph type of stirrer (MR 2000, Kelheim, Germany).

\subsection{Computational Details}

In order to study the direction of binding of MNZ with SWCNT, all calculations reported in this study were obtained by applying the gradient-corrected DFT method with the M06-2X functional ${ }^{77}$ as implemented in the Gaussian 03 program package ${ }^{78}$ Geometries of the investigated species were fully optimized at $6-31+\mathrm{G}(\mathrm{d}, \mathrm{p})$ basis sets. The optimized geometries were confirmed to have no imaginary frequency of the Hessian. Molecules of the solvent have a considerable effect on the stability and reactivity of the chemical compounds, which also affect the kinetics and mechanism of the reactions. In this study, the Polarizable-Continuum Model (PCM $)^{79}$ was utilized to investigate solute-solvent interactions in aqueous solution. The frequency calculations were carried out on the optimized geometries of the metronidazole drug beside SWCNT to consider the zero-point energy in the evaluation of the electronic energies. The armchair $(5,5)$ SWCNT was employed to investigate the interaction between SWCNT and metronidazole drug.

\subsection{Preparation of Sensors}

The unmodified CPE was prepared by thoroughly mixing of analytical grade graphite powder and paraffin oil, in 80:20 / $(\mathrm{w} / \mathrm{w}, \%)$ ratio. The modified CPE (SWCNT-IL/CPE) was prepared by mixing different percentages of graphite powder, IL, and SWCNT. The mixture was blended in a mortar for about $10 \mathrm{~min}$ to become homogeneous. The paste was put into an end of a Teflon holder in which electrical contact was constructed with a copper rod that runs through the center of the electrode body. The electrode surface was polished with $0.3 \mu \mathrm{m} \mathrm{Al} \mathrm{O}_{3}$, then rinsed with deionized water to produce reproducible working surface.

The electrochemical behaviour of metronidazole at these different electrodes was investigated using differential pulse voltammetry (DPV) technique (Table 1). Best results were obtained at 76:20:4 / (w/w, \%) ratio of graphite powder, IL, and SWCNT. This optimized electrode composition was then applied to the voltammetry determination of metronidazole in food samples.
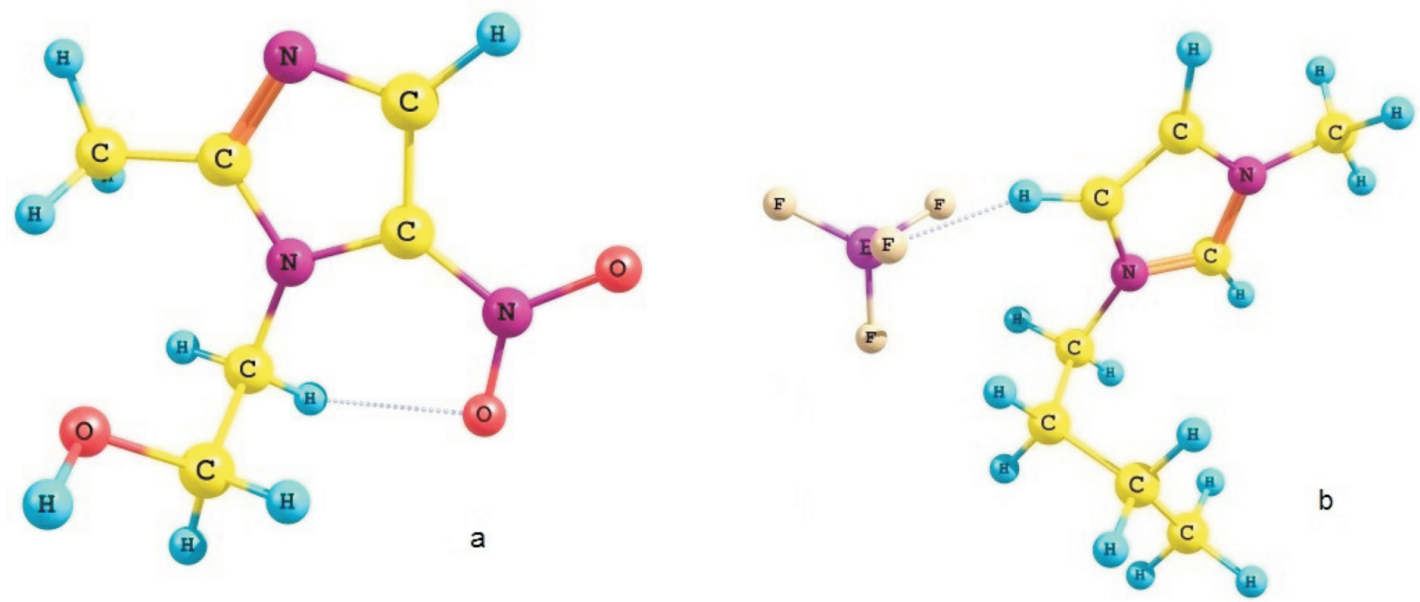

Figure 1 (a) Optimized structure of Metronidazole (MNZ). (b) Structure of 1-butyl-3-methylimidazolium tetrafluroborate $\left[\mathrm{BMIM}^{+}\right]\left[\mathrm{BF}_{4}-\right]$. 
Table 1 Optimization of composition of carbon paste electrode $(n=5)$.

\begin{tabular}{|c|c|c|c|c|c|c|c|}
\hline \multirow[t]{2}{*}{ Electrode no. } & \multicolumn{4}{|c|}{ Composition of carbon paste $/$ wt $\%$} & & \multirow{2}{*}{$\begin{array}{c}\mathrm{I} \\
/ \mu \mathrm{A} \text { in } 0.001 \mathrm{mg} \mathrm{L}^{-1}\end{array}$} & \multirow[t]{2}{*}{$\%$ Error } \\
\hline & Binder & & Graphite powder & $\mathrm{CNT}$ & & & \\
\hline 1 & Paraffin oil & 15 & 85 & SWCNT & 0 & 0.393 & 2.4 \\
\hline 2 & Paraffin oil & 20 & 80 & SWCNT & 0 & 0.954 & 3.2 \\
\hline 3 & Paraffin oil & 25 & 75 & SWCNT & 0 & 0.867 & 2.7 \\
\hline 4 & Paraffin oil & 20 & 79 & SWCNT & 1 & 0.750 & 1.0 \\
\hline 5 & Paraffin oil & 20 & 78 & SWCNT & 2 & 0.792 & 2.1 \\
\hline 6 & Paraffin oil & 20 & 77 & SWCNT & 3 & 1.041 & 1.9 \\
\hline 7 & Paraffin oil & 20 & 76 & SWCNT & 4 & 1.329 & 4.5 \\
\hline 8 & Paraffin oil & 20 & 75 & SWCNT & 5 & 1.107 & 2.3 \\
\hline 9 & Ionic liquid & 20 & 76 & SWCNT & 4 & 7.970 & 4.6 \\
\hline 10 & Ionic liquid & 20 & 76 & MWCNT & 4 & 7.510 & 3.7 \\
\hline
\end{tabular}

\subsection{General Analytical Procedure}

The pH 7.0 Britton-Robinson (B-R) buffer solution was applied as the supporting electrolyte in the experiment. The electrolyte solution was purged with nitrogen for nearly $10 \mathrm{~min}$ and retained under the nitrogen atmosphere during the measurements. The modified electrode was immersed in the sample solution containing an appropriate concentration of MNZ and after stirring for $30 \mathrm{~s}$, DPV curves were recorded from -1.0 to $-0.5 \mathrm{~V}$. The MNZ reduction peak currents were measured at $-0.7 \pm 0.05 \mathrm{~V}$. The pulse amplitude, pulse width and pulse period were $0.4 \mathrm{~s}, 50 \mathrm{mV}$ and $0.05 \mathrm{~s}$, respectively. A cleaning-up procedure in ensuring repeatability of the measurements was followed by a cleaning-up step in supporting electrolyte for at least $10 \mathrm{~min}$. The cleaning/renewing steps were applied between each measurement. Thus, by applying the cleaning-up step and correcting for background currents the background current was about zero in working range.

According to previous works done by researchers, one irreversible peak observed at about $-0.7 \mathrm{~V}$ by $\mathrm{CV}$ method in both Peng et al. ${ }^{64}$ and Lü et al. ${ }^{60}$ works. This peak is related to the catalytic reduction nitro group as explained in the following (cf. Scheme 1). Peng et al. reduced metronidazole by using graphene and ionic liquid composite film modified electrode and Lủ et al. applied MWCNT-film coated glassy carbon electrode for reduction of metronidazole. In both works observed reduction peak in about -0.7 in $7-9 \mathrm{pH}$. Our goal was quantitative analysis and determination of trace amounts of drug that applied DPV method. For this reason CV study not investigated and we rely on their results.

Furthermore, theoretical calculation by DFT method conforms interaction drug with SWNT through $\mathrm{NO}_{2}$ group in metronidazole is the most appropriate orientation that explained in the next section.

\section{Results and Discussion}

\subsection{Optimization of Parameters for Metronidazole Detection}

\subsubsection{Optimization of Electrode Composition}

SWCNT-IL/CPE composition optimization was performed with one-parameter-at-a-time in the constant conditions of voltammetry determination, so that the sum of all the materials is $0.1 \mathrm{~g}$. For optimization purposes, initially, the bare CPE electrodes were prepared with different amounts of graphite and paraffin and without SWCNT. The resulted electrodes in each case were applied to determine metronidazole. The obtained results indicated that the maximum response for the modified sensor is in the amount of paraffin to graphite at the ratio of $0.020 / 0.080 \mathrm{~g}$, respectively. At first, increasing amount of graphite in CPE electrode increased the electrode response probably because of high electron transferring capability of graphite. Spectroscopic grade graphite with extremely porous media caused high charging currents due to decrease of the signal-tonoise ratio in electroanalytical measurements. ${ }^{56}$ The amount of the pasting liquid has a great impact on the response. Higher amounts of the pasting liquid decrease electron transfer rates and led to background current contributions ${ }^{80}$ The presence of higher amounts of binder (paraffin more than $0.020 \mathrm{~g}$ ) in the CPE electrode structure led to a decrease in electrode response due to the decrease of electrode surface conductivity which was the result of the insulting effect of the binder. The influence of the amount of SWCNTs on the current peak has been examined in the range of $(0.001-0.005 \mathrm{~g})$ and $0.004 \mathrm{~g}$ was obtained as the optimum amount for the present study due to providing more recognition sites on the electrode surface. Enhancing the amount of SWCNT in the SWCNT-CPE modified electrode might increase the sensor response. However, increasing the SWCNT amount more than $0.004 \mathrm{~g}$ led to a decrease in the modified sensor response. This phenomenon might be the result of electrode surface saturation. By changing the type of binder from paraffin to ionic liquid, the sensor response was increased approximately 8 times. Finally, by changing the type of CNT from SWCNT to multi-walled carbon nanotube (MWCNT) caused a decrease in the current response (Table 1). Figure 2 shows DP voltammograms of $1.00 \times 10^{-3} \mathrm{mg} \mathrm{L}^{-1}$ of metronidazole at the surface of variety electrodes.

\subsubsection{Selection of Supporting Electrolyte}

The selection of appropriate supporting electrolyte has high importance in achievement of excellent electrochemical responses

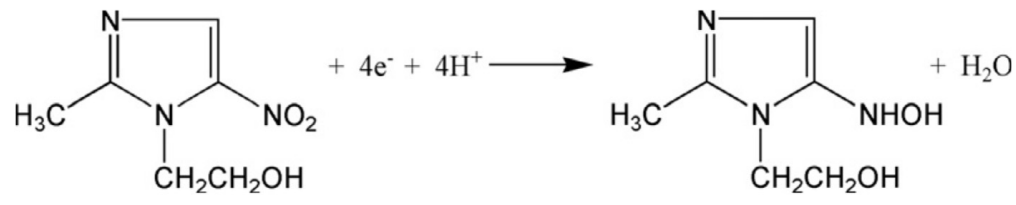

Scheme 1 


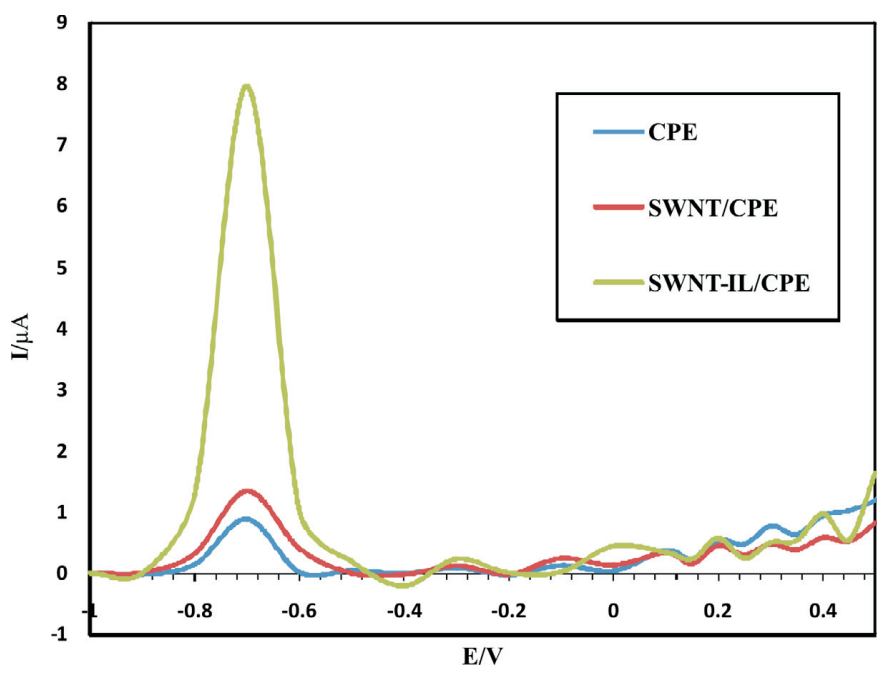

Figure 2 DP voltammograms of $1.00 \times 10^{-3} \mathrm{mg} \mathrm{L}^{-1}$ of metronidazole at the surface of variety electrodes. (Measurement conditions: $\mathrm{pH}=7$, $\mathrm{t}_{\text {equilibrium }}=30 \mathrm{~s}$, stirring rate $=200 \mathrm{rpm}$, scan rate $\left.=25 \mathrm{mV} \mathrm{s}^{-1}\right),(n=5)$.

in the electrochemical determination. In this work, the electrochemical reduction responses of MNZ in different supporting electrolytes such as sodium citrate- $\mathrm{HCl}$ buffer, phosphate buffer, sodium tetraborate $-\mathrm{NaOH}$ and $\mathrm{B}-\mathrm{R}$ solution (each $0.04 \mathrm{M}$ ), were studied by DPV. A clear peak and highest peak current were seen in the B-R solution. Therefore, $0.04 \mathrm{M} B-\mathrm{R}$ solution was chosen as supporting electrolyte.

\subsubsection{Effect of $p H$}

The influence of $\mathrm{pH}$ value on the current response and peak potential of $0.001 \mathrm{mg} \mathrm{L}^{-1} \mathrm{MNZ}$ at the SWCNT-IL/CPE was examined by DPV with $0.04 \mathrm{MB}$ - $\mathrm{R}$ solution in the $\mathrm{pH}$ range from 2.0 to 10.0. As can be seen in Fig. 3 (blue curve) the $\mathrm{I}_{\mathrm{p}}$ increases with an increase in $\mathrm{pH}$ value from 2.0 to 7.0 , then decreases with an increasing of $\mathrm{pH}$ value from 7.0 to 10.0 . Therefore the optimum $\mathrm{pH}$ of B-R solution was selected at 7.0. The relationship between the reduction peak potential (E) and $\mathrm{pH}$ was also exhibited in Fig. 3 (red curve). A linear shift of $\mathrm{E}_{\mathrm{p}}$ toward negative potential with an increasing $\mathrm{pH}$ from 2.0 to 10.0 indicates that protons are directly involved in the reduction of MNZ by obeying the following equation:

$$
\mathrm{E}=-0.3577-0.0498 \mathrm{pH}\left(\mathrm{R}^{2}=0.9987\right)
$$

According to the Nernst equation:

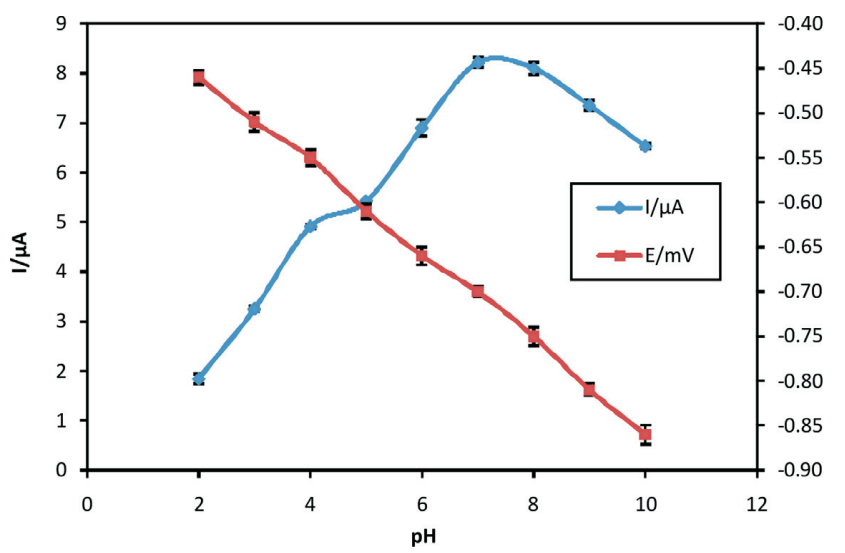

Figure 3 Influence of $\mathrm{pH}$ on the reduction peak current and potential of metronidazole at the SWCNT-IL/CPE electrode (Experimental conditions: metronidazole $\left(1.00 \times 10^{-3} \mathrm{mg} \mathrm{L}^{-1}\right), \mathrm{t}_{\text {equilibrium }}=30 \mathrm{~s}$, stirring rate $=$ $200 \mathrm{rpm}$, scan rate $\left.=25 \mathrm{mV} \mathrm{s}^{-1}\right),(\mathrm{n}=3)$.

$$
\mathrm{E}=\mathrm{E}^{0}-\left(\frac{2.303 \mathrm{mRT}}{\mathrm{nF}}\right) \mathrm{pH}
$$

where $\mathrm{m}$ and $\mathrm{n}$ are corresponding to the transference numbers of proton and electron, respectively; ${ }^{81}$ the ratio of $\mathrm{m} / \mathrm{n}$ was calculated nearly to be 1 , suggesting the numbers of the involved protons and electrons were equal in the electroreduction of MNZ.

\subsubsection{Effect of Stirring Rate}

Whereas the electrode has small contacting surface area with the metronidazole in the medium, the analyte diffusion into the electrode must be affected by the stirring rate of the solution. Therefore the stirring rate was optimized in the range of (200-1000). Metronidazole voltammetry response increased with an increase in the stirring rate up to $400 \mathrm{rpm}$ due to increase of analyte diffusion into the electrode surface. By the continuous increasing of stirring rate, there was a significant decrease in the reduction current. This phenomenon is attributed due to decrease in the time of effective contacting between electrode surface and analyte. Therefore the value of $400 \mathrm{rpm}$ was selected as the optimum stirring rate for the rest of the experiment.

\subsubsection{Effect of Equilibrium Time and Scan Rate}

The influence of equilibrium time on the DPV peak current in the presence of $0.001 \mathrm{mg} \mathrm{L}^{-1}$ metronidazole was also investigated. Variation of the equilibrium time in the range of $(0-480 / \mathrm{s})$ indicated that the reduction peak current of metronidazole increased with increasing of the equilibrium time up to $60 \mathrm{~s}$. Gentle equalizing at the period longer than $60 \mathrm{~s}$, may be due to saturation of the electrode surface. This phenomenon indicates that the electrode process is controlled by diffusion of MNZ to the electrode surface, which is favourable for quantitative determination. The optimized equilibrium time of $60 \mathrm{~s}$ was applied through the experiment due to good sensitivity and rather short analysis time. The scan rate of the modified electrode was survived in the range of $\left(10-100 \mathrm{mV} \mathrm{s}^{-1}\right)$. Experiments indicated that by increasing the scan rate up to $50 \mathrm{mV}^{\mathrm{s}-1}$ the peak current increased due to high electron transfer rate. By continuous increasing of the scan rate there is a decrease in the peak current because of the short time for reduction process. Therefore, a scan rate of $50 \mathrm{mV} / \mathrm{s}$ was selected for subsequent studies.

\subsection{Performance of the Sensor}

\subsubsection{Calibration Curve}

The optimized parameters were applied in the plotting of calibration curve in the concentration range of $5.00 \times 10^{-5}-$ $5.00 \times 10^{-3} \mathrm{mg} \mathrm{L}^{-1}$. Differential pulse voltammetry in the potential range of $\left(-1-0 / \mathrm{V} \mathrm{s}^{-1}\right)$ was applied. The voltammetry responses of the SWCNT-IL/CPE electrode are shown in Fig. 4. The linear regression equation is as follows:

z $\quad \mathrm{I}_{\mathrm{p}}(\mu \mathrm{A})=914.92 \mathrm{C}_{\mathrm{MNZ}}+6.3839\left(\mathrm{r}^{2}=0.9315\right)$

In the lower concentrations of $5.00 \times 10^{-5} \mathrm{mg} \mathrm{L}^{-1}$ no linear plot was achieved that might due to somehow low sensitivity of DPV method; on the other hand, in higher concentrations than $5.00 \times$ $10^{-3} \mathrm{mg} \mathrm{L}^{-1}$ there is no linearity between reduction peak current and concentration due to the saturation of electrode surface.

\subsubsection{Limit of Detection (LOD) and Limit of Quantification (LOQ)}

The limit of detection (LOD) and limit of quantification (LOQ) were calculated using the relation as follows: $\mathrm{kS}_{\mathrm{b}} / \mathrm{m}$, where $\mathrm{k}=3$ for LOD and $\mathrm{k}=10$ for LOQ, $\mathrm{S}_{\mathrm{b}}$ represented the standard deviation of the peak currents of the blank $(n=5)$ and m represented 


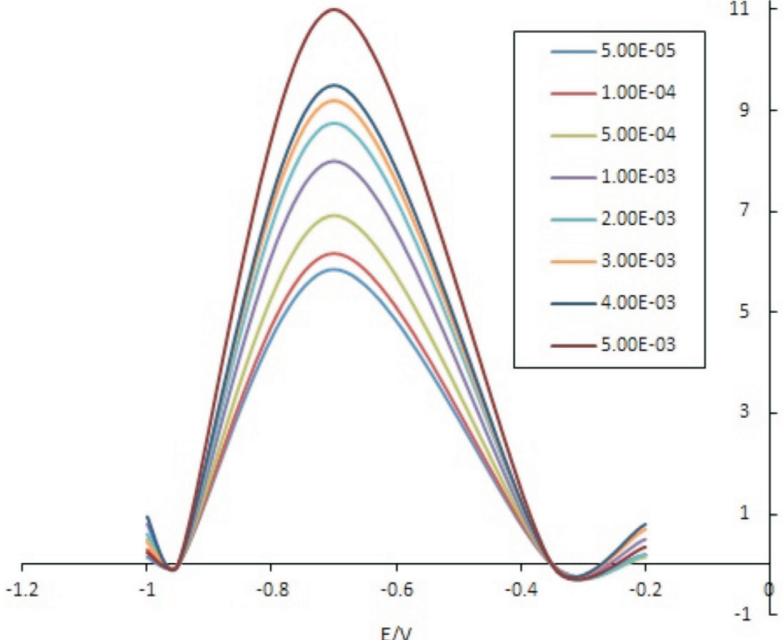

Figure 4 DPV signal variation with changing the metronidazole concentration/mg L $\mathrm{m}^{-1}$ onto SWCNT-IL/CPE electrode. (Measurement conditions: stirring rate $400 \mathrm{rpm}, \mathrm{pH}=7, \mathrm{t}_{\text {equilibrium }}=60 \mathrm{~s}$, scan rate $=50 \mathrm{mV} \mathrm{s}^{-1}$, pulse amplitude $=50 \mathrm{mV}$, pulse width $=40 \mathrm{~ms}),(n=3)$.

the slope of the calibration curve for metronidazole. Both LOD and LOQ values were found to be $1.238 \times 10^{-5} \mathrm{mg} \mathrm{L}^{-1}$ and $4.127 \times$ $10^{-5} \mathrm{mg} \mathrm{L}^{-1}$, respectively. These values indicated the high sensitivity of the proposed method for determination of MNZ. The comparison of proposed sensor with other reported sensors for MNZ determination was summarized in Table 2.

\subsubsection{Reproducibility, Stability of SWCNT-IL/CPE and Interference Study}

To investigate the reproducibility of the prepared sensor, MNZ solution with the concentration of $0.001 \mathrm{mg} \mathrm{L}^{-1}$ was measured using five SWCNT-CPE/IL modified electrodes prepared severally under the same experimental conditions. The relative standard deviation (RSD) was $4.7 \%$. The repeatability of the same electrode was also examined for $0.001 \mathrm{mg} \mathrm{L}^{-1}$ of MNZ. The RSD for five replicate measurements was $3.6 \%$.

For evaluating the stability of the electrode, the peak current variation of $0.001 \mathrm{mg} \mathrm{L}^{-1} \mathrm{MNZ}$ was measured daily. When accumulated in air at room temperature, the sensor can retain $95.5 \%$ of its initial response after after 12 days, and decreased to after 25 days. These results show that the prepared sensor has satisfactory reproducibility and applicable stability for the recognition of MNZ.

The interference study was performed for drugs such as doxycycline, lidocaine, metformin, aspirin, acetaminophen and $\mathrm{NH}_{4}^{+}, \mathrm{Ca}^{2+}, \mathrm{Mg}^{2+}$ that were available in the same concentration analyte and the100-fold analyte. In these experiments applied optimum condition and concentration of metronidazole was
$0.001 \mathrm{mg} . \mathrm{L}^{-1}$.These drugs and cations have interference with metronidazole neither in terms of peak situation nor in terms of decrease of intensity peak. According to the definition of the tolerant limit, this is the maximum concentration of the interfering substance or compound that causes $5 \%$ or more error on the potential peak desired drug. The results showed that to 100 -fold of analyte concentration not observed any interference. The higher concentrations were not used.

\subsubsection{Application in Real Sample Analysis}

\subsubsection{Preparation of the Real Samples}

Homogenized egg or milk powder samples were weighed $(0.100 \mathrm{~g})$ exactly into a $10 \mathrm{~mL}$ polypropylene centrifugal tube. Then, $5 \mathrm{~mL}$ of $10 \%$ (wt \%) trichloroacetic acid was added into the tube and vortexed extremely for $1 \mathrm{~min}$, then centrifuged at $4000 \mathrm{rpm}$ for $10 \mathrm{~min}$ and separated additional compositions out a $0.5 \mu \mathrm{m}$ filter membrane. The filtrate was diluted to $25 \mathrm{~mL}$ with B-R solution $\mathrm{pH} 7.0$ for detection.

\subsubsection{Results of Determination}

In order to evaluate the performance of the modified carbon paste electrode in practical analytical applications, quantitation of MNZ in egg and milk samples by using standard addition method with spiking samples to standard solutions were attempted. The results are given in Table 3. Although the egg and milk have complex matrix the results were satisfactory.

\subsection{DFT Calculations}

The SWCNT and metronidazole drug can interact with each other in the van der Waals manner. In this study, four possible van der Waals interactions were investigated. Their geometries have been fully optimized in the aqueous solution using the PCM model. Their PCM optimized geometries are presented in Fig. 5. The optimized geometries were named as SD1 to SD4, respectively. In the optimized geometries, all the substituents were in the same plane with the aromatic imidazole ring.

In the SD1 geometry, the metronidazole drug was parallel to the nanotube, the $-\mathrm{CH}_{2}-\mathrm{CH}_{2}-\mathrm{OH}$ moiety was far from the nanotube. The distance between the imidazole aromatic ring of the drug and SWCNT was about $350 \mathrm{pm}$.

On the other hand, in the SD2 geometry, the $-\mathrm{CH}_{2}-\mathrm{CH}_{2}-\mathrm{OH}$ moiety was close to the nanotube. The distance between the $\mathrm{O}$ atom of the hydroxyl group and the carbon nanotube was about $300 \mathrm{pm}$, which was about $600 \mathrm{pm}$ in the SD1 geometry. The drug lay at the edge of the SWCNT. In this structure, the imidazole ring of the drug was roughly parallel with respect to the six-membered rings of the SWCNT. Their distance was about $375 \mathrm{pm}$. Both the imidazole ring and hydroxyl moieties were close to the SWCNT.

Table 2 Comparison of features of proposed sensor with other literature data on the determination of metronidazole.

\begin{tabular}{lllllll}
\hline Electrode & Technique & \multicolumn{1}{c}{$\begin{array}{c}\text { Linear range } \\
/ \mathrm{mg} \mathrm{L}^{-1}\end{array}$} & $\begin{array}{c}\text { LOD } \\
/ \mathrm{mg} \mathrm{L}^{-1}\end{array}$ & $\begin{array}{c}\text { R.S.D. } \\
/ \%\end{array}$ & $\mathrm{pH}$ & \multicolumn{2}{c}{ Peak potential } \\
$/ \mathrm{V}$
\end{tabular}




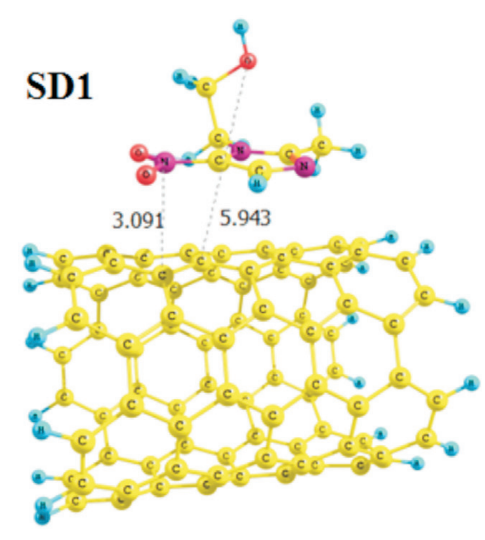

SD3

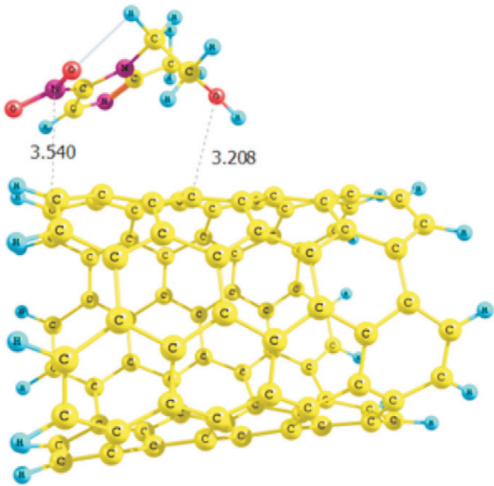

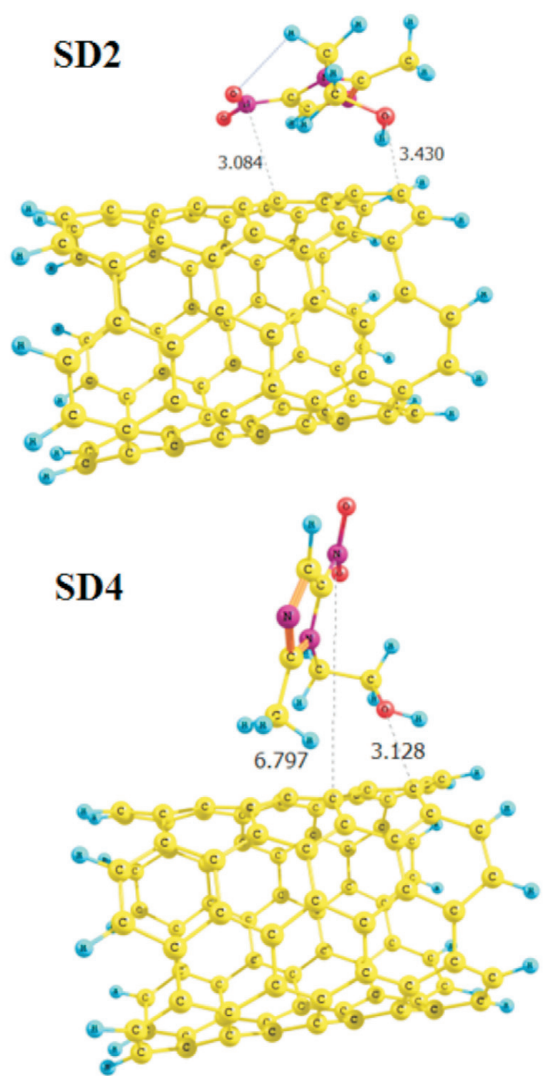

Figure 5 The optimized geometries for exploring the van der Waals interactions between the metronidazole drug and $(5,5)$ SWCNT in four state SD1, SD2, SD3, SD4.

In the SD3 structure, the hydroxyl group was close to the CNT, but other part of the molecule was far from the SWCNT. The aromatic ring was roughly parallel to the rings of the SWCNT by a dihedral angle of about 15. Finally, in the SD4 geometry, the plane of the drug was perpendicular to the SWCNT. The methyl and $-\mathrm{CH}_{2}-\mathrm{CH}_{2}-\mathrm{OH}$ moieties were close to the SWCNT. Important distances are illustrated in Fig. 5.

The binding energy of the van der Waals interaction was computed between the metronidazole drug and the SWCNT in

Table 3 Determination of metronidazole in real samples intraday $(n=5)$.

\begin{tabular}{lllll}
\hline Sample & Added $/ \mathrm{mg} \mathrm{L}^{-1}$ & Found $/ \mathrm{mg} \mathrm{L}^{-1}$ & Recovery/\% & \% Error \\
\hline Egg & 0 & ND & & \\
& $1.00 \mathrm{E}-03$ & $1.07 \mathrm{E}-03$ & 107 & \pm 4.5 \\
& $3.00 \mathrm{E}-03$ & $2.71 \mathrm{E}-03$ & 90.33 & \pm 3.9 \\
& $5.00 \mathrm{E}-03$ & $4.59 \mathrm{E}-03$ & 91.8 & \pm 4.9 \\
Milk & 0 & ND & & \\
& $1.00 \mathrm{E}-03$ & $1.08 \mathrm{E}-03$ & 108 & \pm 4.5 \\
& $3.00 \mathrm{E}-03$ & $2.81 \mathrm{E}-03$ & 93.66 & \pm 3.7 \\
& $5.00 \mathrm{E}-03$ & $4.59 \mathrm{E}-03$ & 91.8 & \pm 5
\end{tabular}

several orientations. The obtained-DFT results are presented in Table 4 . The binding energy is defined as:

$$
\Delta \mathrm{E}=\mathrm{E}_{(\mathrm{SWNT}-\text { Drug })}-\left(\mathrm{E}_{(\mathrm{SWNT})}+\mathrm{E}_{(\text {(Drug })}\right)
$$

Where the $\mathrm{E}_{(\mathrm{SWNT} \text { - Drug) }}\left(\mathrm{E}_{(\mathrm{SWNT})}\right.$ and $\mathrm{E}_{\text {(Drug) }}$ are the electronic energies of the investigated species; the optimized geometry of the drug and SWCNT beside each other, the SWCNT and the metronidazole drug, respectively.

As seen, the order of the DFT-calculated binding energy of the optimized geometries is SD2 > SD1 > SD3 > SD4. Since, the SD2 geometry is the most favourable structure for the van der Waals interaction between the used SWCNT and the metronidazole Drug. Energy difference between the SD2 geometry and each of the SD1, SD3 and SD4 geometries is 11.58, 13.16 and $29.55 \mathrm{~kJ} \mathrm{~mol}^{-1}$, respectively.

\section{Conclusion}

In the present study, we have been able to demonstrate a new and highly sensitive modified electrochemical sensor for the detection of trace amounts of MNZ by SWCNT-IL/CPE electrode by applying simple, rapid and precise DPV technique. So, the redox reaction of the electroactive nitro group on $\mathrm{MNZ}$ was

Table 4 The electronic energy of the optimized geometries in Hartree together with the binding energy of the investigated interactions $\Delta \mathrm{E} / \mathrm{kJ} \mathrm{mol}^{-1}$.

\begin{tabular}{lcccccc}
\hline Interaction & SWCNT & MNZ & $\begin{array}{c}\text { SWCNT-MNZ } \\
\text { complex }\end{array}$ & $\begin{array}{c}\Delta \mathrm{E} \\
/ \text { Hartree }\end{array}$ & $\begin{array}{c}\text { BSSE Energy } \\
\text { Corrected } \Delta \mathrm{E} \\
/ \mathrm{KJ} \mathrm{mol}^{-1}\end{array}$ \\
\hline SD1 & -3440.6041857 & -623.6451215 & -4064.2671261 & -0.0178189 & 0.006959704 & -28.51 \\
SD2 & -3440.6041857 & -623.6451215 & -4064.2715396 & -0.0222324 & 0.009014332 & -34.70 \\
SD3 & -3440.6041857 & -623.6451215 & -4064.2665264 & -0.0172192 & 0.007775481 & -24.79 \\
SD4 & -3440.6041857 & -623.6451215 & -4064.2602834 & -0.0109762 & 0.005193646 & -15.18 \\
\hline
\end{tabular}


applied for recognition. The combination of the high conductivity of IL and the unique properties of SWCNT, like high specific surface area, subtle electronic properties and strong adsorptive ability, enhanced the sensitivity of the modified electrode, interestingly. The modified electrode demonstrated a strong response toward the reduced form of MNZ over a wide range of concentration from $5.00 \times 10^{-5}$ to $5.00 \times 10^{-3} \mathrm{mg} \mathrm{L}^{-1}$ with a detection limit of $1.238 \times 10^{-5} \mathrm{mg} \mathrm{L}^{-1}$ which is much lower than that of any other reported study up to now. It is evident that the proposed method can provide wide linear range and lower detection limit by a simple electrode preparation procedure. Owing to high sensitivity, broad linearity, good stability, excellent reproducibility of the modified electrode, the proposed sensor could be applied in pharmaceuticals and real sample analysis. Using the DFT method, the non-covalent interactions of the metronidazole with the SWCNT were investigated in four different manners. Among them, the most stable form involved the interaction of metronidazole with the SWCNT via the nitrogen atom of the nitro group.

\section{Acknowledgements}

The authors acknowledge Islamic Azad University of Mashhad (IAUM) Research Council for financial support of this work.

\section{References}

1 S. Marks, S. Rankin, B. Byrne and J. Weese, Enteropathogenic bacteria in dogs and cats: diagnosis, epidemiology, treatment, and control, J. Vet. Intern. Med., 2011, 25, 1195-1208.

2 P. Zuman and Z. Fijaiek, Reaction of electrogenerated arylhydroxylamines and nitrosobenzene in the course of reduction of nitrobenzene under conditions of cyclic voltammetry, J. Electroanal. Chem. Interfacial Electrochem., 1990, 296, 589-593.

3 X. Xia, X. Li, S. Ding, S. Zhang, H. Jiang, J. Li and J. Shen, Determination of 5-nitroimidazoles and corresponding hydroxy metabolites in swine kidney by ultra-performance liquid chromatography coupled to electrospray tandem mass spectrometry, Anal. Chim. Acta, 2009, $637,79-86$.

4 N. Tavakoli, J. Varshosaz, F. Dorkoosh and M. R. Zargarzadeh, Development and validation of a simple HPLC method for simultaneous in vitro determination of amoxicillin and metronidazole at single wavelength, J. Pharm. Biomed. Anal., 2007, 43, 325-329.

5 M. Gaugain and J. Abjean, High-performance thin-layer chromatographic method for the fluorescence detection of three nitroimidazole residues in pork and poultry tissue, J. Chromatogr. A., 1996, 737, 343-346.

6 S. Bhatia and V. Shanbhag, Electron-capture gas chromatographic assays of 5-nitroimidazole class of antimicrobials in blood, $J$. Chromatogr. B: Biomed. Sci. Appl., 1984, 305, 325-334.

7 P. Nagaraja, K. Sunitha, R. Vasantha and H. Yathirajan, Spectrophotometric determination of metronidazole and tinidazole in pharmaceutical preparations, J. Pharm. Biomed. Anal., 2002, 28, 527-535.

8 T. Saffaj, M. Charrouf, A. Abourriche, Y. Abboud, A. Bennamara and M. Berrada, Spectrophotometric determination of metronidazole and secnidazole in pharmaceutical preparations, Il Farmaco, 2004, 59, 843-846.

9 P. Parimoo, C. Prasad and R. Vineeth, Simultaneous quantitative determination of metronidazole and nalidixic acid in tablets by difference spectroscopy, J. Pharm. Biomed. Anal., 1996, 14, 389-393.

10 S. Tan, J. Jiang, B. Yan, G. Shen and R. Yu, Preparation of a novel fluorescence probe based on covalent immobilization by emulsion polymerization and its application to the determination of metronidazole, Anal. Chim. Acta, 2006, 560, 191-196.

11 S.A. Özkan, Y. Özkan and Z. Şentürk, Electrochemical reduction of metronidazole at activated glassy carbon electrode and its determination in pharmaceutical dosage forms, J. Pharm. Biomed. Anal., 1998, 17, 299-305.

12 A.M.O. Brett, S.H.P. Serrano, I. Gutz and M.A. La-Scalea, Electrochemical reduction of metronidazole at a DNA-modified glassy carbon electrode, Bioelectrochem. Bioenerg., 1997, 42, 175-178.
13 D. Chen, J. Deng, J. Liang, J. Xie, C. Hu and K. Huang, A core-shell molecularly imprinted polymer grafted onto a magnetic glassy carbon electrode as a selective sensor for the determination of metronidazole, Sens. Actuators, B., 2013, 183, 594-600.

14 A. Salimi, M. Izadi, R. Hallaj and M. Rashidi, Simultaneous determination of ranitidine and metronidazole at glassy carbon electrode modified with single wall carbon nanotubes, Electroanalysis, 2007, 19, 1668-1676.

15 P.N. Bartlett, E. Ghoneim, G. El-Hefnawy and I. El-Hallag, Voltammetry and determination of metronidazole at a carbon fiber microdisk electrode, Talanta, 2005, 66, 869-874.

16 B. Rezaei and S. Damiri, Fabrication of a nanostructure thin film on the gold electrode using continuous pulsed-potential technique and its application for the electrocatalytic determination of metronidazole, Electrochim. Acta, 2010, 55, 1801-1808.

17 Y. Gui, Y.N. Ni, and S. Kokot, Simultaneous determination of three 5-nitroimidazoles in foodstuffs by differential pulse voltammetry and chemometrics, Chin. Chem. Lett., 2011, 22, 591-594.

18 M.B. Gholivand and M. Torkashvand, A novel high selective and sensitive metronidazole voltammetric sensor based on a molecularly imprinted polymer-carbon paste electrode, Talanta, 2011, 84, 905-912.

19 R.N. Goyal, V.K. Gupta and N. Bachheti, Fullerene-C 60-modified electrode as a sensitive voltammetric sensor for detection of nandrolone-an anabolic steroid used in doping, Anal. Chim. Acta, 2007, 597, 82-89.

20 R. Jain, V.K. Gupta, N. Jadon and K. Radhapyari, Voltammetric determination of cefixime in pharmaceuticals and biological fluids, Anal. Biochem., 2010, 407, 79-88.

21 R.N. Goyal, V.K. Gupta and S. Chatterjee, Voltammetric biosensors for the determination of paracetamol at carbon nanotube modified pyrolytic graphite electrode, Sens. Actuators, B., 2010, 149, 252-258.

22 V.K Gupta, A. Nayak, S. Agarwal and B. Singhal, Recent advances on potentiometric membrane sensors for pharmaceutical analysis, Comb. Chem. High Throughput Screening, 2011, 14, 284-302.

23 V.K. Gupta, A.K. Singh, S. Mehtab and B. Gupta, A cobalt (II)-selective PVC membrane based on a Schiff base complex of N, N'-bis (salicylidene)-3, 4-diaminotoluene, Anal. Chim. Acta, 2006, 566, 5-10.

$24 \mathrm{~V}$. Gupta, A. Jain and P. Kumar, PVC-based membranes of N, $\mathrm{N}^{\prime}$-dibenzyl-1, 4, 10, 13-tetraoxa-7, 16-diazacyclooctadecane as $\mathrm{Pb}$ (II)-selective sensor, Sens. Actuators, B., 2006, 120, 259-265.

25 V. Gupta, A. Jain, P. Kumar, S. Agarwal and G. Maheshwari, Chromium (III)-selective sensor based on tri-o-thymotide in PVC matrix, Sens. Actuators, B., 2006, 113, 182-186.

26 A. Jain, V. Gupta, L. Singh and J. Raisoni, A comparative study of $\mathrm{Pb}$ $2+$ selective sensors based on derivatized tetrapyrazole and calix [4] arene receptors, Electrochim. Acta, 2006, 51, 2547-2553.

27 V. Gupta, A. Singh, M. Al Khayat and B. Gupta, Neutral carriers based polymeric membrane electrodes for selective determination of mercury (II), Anal. Chim. Acta, 2007, 590, 81-90.

28 V.K. Gupta, R. Mangla, U. Khurana and P. Kumar, Determination of uranyl ions using poly (vinyl chloride) based 4-tert-butylcalix [6] arene membrane sensor, Electroanalysis, 1999, 11, 573-576.

29 V.K. Gupta, R. Prasad, P. Kumar and R. Mangla, New nickel (II) selective potentiometric sensor based on 5, 7, 12, 14-tetramethyldibenzotetraazaannulene in a poly (vinyl chloride) matrix, Anal. Chim. Acta, 2000, 420, 19-27.

30 V.K. Gupta, L. Singh, R. Singh, N. Upadhyay, S. Kaur and B. Sethi, A novel copper (II) selective sensor based on dimethyl 4, 4'(o-phenylene) bis (3-thioallophanate) in PVC matrix, J. Mol. Liq., 2012, 174, 11-16.

31 V.K. Gupta, B. Sethi, R. Sharma, S. Agarwal and A. Bharti, Mercury selective potentiometric sensor based on low rim functionalized thiacalix [4]-arene as a cationic receptor, J. Mol. Liq., 2013, 177, 114-118.

32 V.K. Gupta, A.K. Jain and G. Maheshwari, Aluminum (III) selective potentiometric sensor based on morin in poly (vinyl chloride) matrix, Talanta, 2007, 72, 1469-1473.

33 V.K. Gupta, A. Jain, S. Agarwal and G. Maheshwari, An iron (III) ion-selective sensor based on a $\mu$-bis (tridentate) ligand, Talanta, 2007, 71, 1964-1968.

34 A. Jain, V. Gupta, U. Khurana and L.P. Singh, A new membrane sensor for UO $22+$ ions based on 2-hydroxyacetophenoneoxime-thioureatrioxane resin, Electroanalysis, 1997, 9, 857-860. 
35 V.K. Gupta, M. Ganjali, P. Norouzi, H. Khani, A. Nayak and S. Agarwal, Electrochemical analysis of some toxic metals by ion-selective electrodes, Crit. Rev. Anal. Chem., 2011, 41, 282-313.

36 V.K. Gupta, R.N. Goyal and R.A. Sharma, Anion recognition using newly synthesized hydrogen bonding disubstituted phenylhydrazone-based receptors: poly (vinyl chloride)-based sensor for acetate, Talanta, 2008, 76, 859-864.

37 R. Prasad, V.K. Gupta and A. Kumar, Metallo-tetraazaporphyrin based anion sensors: regulation of sensor characteristics through central metal ion coordination, Anal. Chim. Acta, 2004, 508, 61-70.

38 V.K. Gupta, S. Jain and U. Khurana, A PVC-based pentathia-15crown-5 membrane potentiometric sensor for mercury (II), Electroanalysis, 1997, 9, 478-480.

39 V.K. Gupta, S. Jain and S. Chandra, Chemical sensor for lanthanum (III) determination using aza-crown as ionophore in poly (vinyl chloride) matrix, Anal. Chim. Acta, 2003, 486, 199-207.

40 V.K. Gupta, S. Chandra and R. Mangla, Dicyclohexano-18-crown-6 as active material in PVC matrix membrane for the fabrication of cadmium selective potentiometric sensor, Electrochim. Acta, 2002, 47, 1579-1586.

$41 \mathrm{~K}$. Vinod, Determination of lead using a poly (vinyl chloride)-based crown ether membrane, Analyst, 1995, 120, 495-498.

42 S.K. Srivastava, V.K. Gupta, M.K. Dwivedi and S. Jain, in Analytical Proceedings including Analytical Communications, Vol. 32, Royal Society of Chemistry, 1995, pp. 21-23.

43 V. Gupta, A. Jain, G. Maheshwari, H. Lang and Z. Ishtaiwi, Copper (II)-selective potentiometric sensors based on porphyrins in PVC matrix, Sens. Actuators, B., 2006, 117, 99-106.

44 A. Jain, V. Gupta and L. Singh, Macrocycle based membrane sensors for the determination of cobalt (II) ions, Analyst, 1997, 122, 583-586.

45 V.K. Gupta, A.K. Jain, L.P. Singh and U. Khurana, Porphyrins as carrier in PVC based membrane potentiometric sensors for nickel(II), Anal. Chim. Acta, 1997, 355, 33-41.

46 H. Karimi-Maleh, K. Ahanjan, M. Taghavi and M. Ghaemy, A novel voltammetric sensor employing zinc oxide nanoparticles and a new ferrocene-derivative modified carbon paste electrode for determination of captopril in drug samples, Anal. Methods, 2016, 8, 1780-1788.

47 H. Karimi-Maleh, P. Biparva and M. Hatami, A novel modified carbon paste electrode based on $\mathrm{NiO} / \mathrm{CNTs}$ nanocomposite and $(9$, 10-dihydro-9, 10-ethanoanthracene-11, 12-dicarboximido)-4-ethylbenzene-1, 2-diol as a mediator for simultaneous determination of cysteamine, nicotinamide adenine dinucleotide and folic acid, Biosens. Bioelectron., 2013, 48, 270-275.

48 H. Karimi-Maleh, F. Tahernejad-Javazmi, A.A. Ensafi, R. Moradi, S. Mallakpour and H. Beitollahi, A high sensitive biosensor based on $\mathrm{FePt} / \mathrm{CNTs}$ nanocomposite/N-(4-hydroxyphenyl)-3, 5-dinitrobenzamide modified carbon paste electrode for simultaneous determination of glutathione and piroxicam, Biosens. Bioelectron., 2014, 60, 1-7.

49 R. Moradi, S. Sebt, H. Karimi-Maleh, R. Sadeghi, F. Karimi, A. Bahari and $\mathrm{H}$. Arabi, Synthesis and application of FePt/CNTs nanocomposite as a sensor and novel amide ligand as a mediator for simultaneous determination of glutathione, nicotinamide adenine dinucleotide and tryptophan, Phys. Chem. Chem. Phys., 2013, 15, 5888-5897.

50 A.A. Ensafi and H. Karimi-Maleh, Modified multiwall carbon nanotubes paste electrode as a sensor for simultaneous determination of 6-thioguanine and folic acid using ferrocenedicarboxylic acid as a mediator, J. Electroanal. Chem., 2010, 640, 75-83.

51 M.R. Shahmiri, A. Bahari, H. Karimi-Maleh, R. Hosseinzadeh and N. Mirnia, Ethynylferrocene-NiO/MWCNT nanocomposite modified carbon paste electrode as a novel voltammetric sensor for simultaneous determination of glutathione and acetaminophen, Sens. Actuators, B., 2013, 177, 70-77.

52 A.A. Ensafi, H. Karimi-Maleh, S. Mallakpour and M. Hatami, Simultaneous determination of $\mathrm{N}$-acetylcysteine and acetaminophen by voltammetric method using $\mathrm{N}$-(3, 4-dihydroxyphenethyl)-3, 5 -dinitrobenzamide modified multiwall carbon nanotubes paste electrode, Sens. Actuators, B., 2011, 155, 464-472.

53 J.B. Raoof, R. Ojani and H. Karimi-Maleh, Carbon paste electrode incorporating 1-[4-(ferrocenyl ethynyl) phenyl]-1-ethanone for electrocatalytic and voltammetric determination of tryptophan, Electroanalysis, 2008, 20, 1259-1262.

54 H. Yaghoubian, H. Karimi-Maleh, M.A. Khalilzadeh and F. Karimi,
Electrocatalytic oxidation of levodopa at a ferrocene modified carbon nanotube paste electrode, Int. J. Electrochem. Sci, 2009, 4, 993-1003.

55 V.K. Gupta, H. Karimi-Maleh and R. Sadegh, Simultaneous determination of hydroxylamine, phenol and sulfite in water and waste water samples using a voltammetric nanosensor, Int. J. Electrochem. Sci, 2015, 10, 303-316.

56 B. Uslu and S.A. Özkan, Electroanalytical application of carbon based electrodes to the pharmaceuticals, Anal. Lett., 2007, 40, 817-853.

57 D. Moscone, D. D'ottavi, D. Compagnone, G. Palleschi and A. Amine, Construction and analytical characterization of Prussian blue-based carbon paste electrodes and their assembly as oxidase enzyme sensors, Anal. Chem., 2001, 73, 2529-2535.

58 C. Almeida and B. Giannetti, A new and practical carbon paste electrode for insoluble and ground samples, Electrochem. Commun., 2002, 4, 985-988.

59 N.S. Lawrence, R.P. Deo and J. Wang, Biocatalytic carbon paste sensors based on a mediator pasting liquid, Anal. Chem., 2004, 76, 3735-3739.

60 S. Lü, K. Wu, X. Dang and S. Hu, Electrochemical reduction and voltammetric determination of metronidazole at a nanomaterial thin film coated glassy carbon electrode, Talanta, 2004, 63, 653-657.

61 Z.S. Stojanović, E. Mehmeti, K. Kalcher, V. Guzsvány and D.M. Stanković, SWCNT-modified carbon paste electrode as an electrochemical sensor for histamine determination in alcoholic beverages, Food. Anal. Method., 2016, 1-10.

62 D.V. Chernyshov, N.V. Shvedene, E.R. Antipova and I.V. Pletnev, Ionic liquid-based miniature electrochemical sensors for the voltammetric determination of catecholamines, Anal. Chim. Acta, 2008, 621, 178-184.

63 W. Sun, Y. Duan, Y. Li, H. Gao and K. Jiao, Electrochemical behaviors of guanosine on carbon ionic liquid electrode and its determination, Talanta, 2009, 78, 695-699.

64 J. Peng, C. Hou and X. Hu, Determination of metronidazole in pharmaceutical dosage forms based on reduction at graphene and ionic liquid composite film modified electrode, Sens. Actuators, B., 2012, $169,81-87$.

65 H. Khani, M. K. Rofouei, P. Arab, V. K. Gupta and Z. Vafaei, Multi-walled carbon nanotubes-ionic liquid-carbon paste electrode as a super selectivity sensor: application to potentiometric monitoring of mercury ion (II), J. Hazard. Mater., 2010, 183, 402-409.

66 E. Afsharmanesh, H. Karimi-Maleh, A. Pahlavan, J. Vahedi, Electrochemical behavior of morphine at $\mathrm{ZnO} / \mathrm{CNT}$ nanocomposite room temperature ionic liquid modified carbon paste electrode and its determination in real samples, J. Mol. Liq., 2013, 181, 8-13.

67 H. Beitollah, M. Goodarzian, M.A. Khalilzadeh, H. Karimi-Maleh, M. Hassanzadeh and M. Tajbakhsh, Electrochemical behaviors and determination of carbidopa on carbon nanotubes ionic liquid paste electrode, J. Mol. Liq., 2012, 173, 137-143.

68 R. Bavandpour, H. Karimi-Maleh, M. Asif, V.K. Gupta, N. Atar and M. Abbasghorbani, Liquid phase determination of adrenaline uses a voltammetric sensor employing $\mathrm{CuFe} 2 \mathrm{O} 4$ nanoparticles and room temperature ionic liquids, J. Mol. Liq., 2016, 213, 369-373.

69 S. Gill, R. Löbenberg, T. Ku, S. Azarmi, W. Roa and E.J. Prenner, Nanoparticles: characteristics, mechanisms of action, and toxicity in pulmonary drug delivery-a review, J. Biomed. Nanotechnol., 2007, 3, 107-119.

70 S. Baruah and J. Dutta, Nanotechnology applications in pollution sensing and degradation in agriculture: a review, Environ. Chem. Lett., 2009, 7, 191-204.

71 M. Aydin, Density functional theory studies on covalent functionalization of single-walled carbon nanotubes with benzenesulfonic acid, Vib. Spectrosc., 2013, 65, 84-93.

72 D. Farmanzadeh and S. Ghazanfary, Interaction of vitamins A, B1, C, B3 and D with zigzag and armchair boron nitride nanotubes: a DFT study, Comptes Rendus Chimie, 2014, 17, 985-993.

73 K. Lou, Z. Zhu, H. Zhang, Y. Wang, X. Wang and J. Cao, Comprehensive studies on the nature of interaction between carboxylated multi-walled carbon nanotubes and bovine serum albumin, Chem.-Biol. Interact., 2016, 243, 54-61.

74 A. Nezhadali and M. Mojarrab, Computational design and multivariate optimization of an electrochemical metoprolol sensor based on molecular imprinting in combination with carbon nanotubes, Anal. Chim. Acta, 2016, 924, 86-98. 
75 N. Sa, G. Wang, B. Yin and Y. Huang, Theoretical study on non-covalent functionalization of armchair carbon nanotube by tetrathiafulvalene molecule, Phys. E, 2008, 40, 2396-2399.

76 Y. Wang, F. Xing, H. Zhang and K. Lou, Experimental and theoretical investigation on the interaction of carboxylic multi-walled carbon nanotubes with bisphenol AF, Colloids Surf., A, 2016, 497, 45-52.

77 C. Lee, W. Yang and R. G. Parr, Development of the Colle-Salvetti correlation-energy formula into a functional of the electron density, Phys. Rev. B., 1988, 37, 785.

78 M. Frisch, G. Trucks, H. Schlegel, G. Scuseria, M. Robb, J. Cheeseman, J. Montgomery Jr, T. Vreven, K. Kudin and J. Burant, Gaussian 03,
Revision B. 03, Gaussian, Inc., Wallingford, CT, 2004. Gaussian 03, Revision B. 05, M.J. Frisch, et al., Gaussian, Inc., Pittsburgh, PA, 2003.

79 R. Cammi and J. Tomasi, Remarks on the use of the apparent surface charges (ASC) methods in solvation problems: iterative versus matrix-inversion procedures and the renormalization of the apparent charges, J. Comput. Chem., 1995, 16, 1449-1458.

80 I. Švancara, K. Vytřas, J. Barek and J. Zima, Carbon paste electrodes in modern electroanalysis, Crit. Rev. Anal. Chem., 2001, 31, 311-345.

81 C. Zhou, Z. Liu, Y. DongV D. Li, Electrochemical behavior of o-nitrophenol at hexagonal mesoporous silica modified carbon paste electrodes, Electroanalysis, 2009, 21, 853-858. 